\title{
INFLUENCE OF INDIVIDUAL AND COMMUNITY-LEVEL ASSOCIATES OF CONTRACEPTIVE USE IN PAKISTAN: A MULTI-LEVEL MIXED EFFECT ANALYSIS (PDHS 2017-18)
}

\author{
Asifa Kamal $^{1}$, Sadaf Malik ${ }^{2 *}$, Hafsa Batool ${ }^{3}$, Afza Rasul ${ }^{4}$ \\ $1,2^{*}, 3,4$ Lahore College for Women University, Lahore, Pakistan. \\ Email: ${ }^{1}$ asifa.k53@gmail.com, ${ }^{2 *}$ sadafmalik1324247@ gmail.com, ${ }^{3}$ batooleconomist@gmail.com, ${ }^{4}$ afzarasul@gmail.com
} Article History: Received on $19^{\text {th }}$ May 2021, Revised on $28^{\text {th }}$ May 2021, Published on $6^{\text {th }}$ June 2021

\section{Abstract}

Purpose of the study: This research aims to investigate the impact of mass media exposure and women's autonomy on the use of contraceptives, along with other potential determinants at the individual level and community level among women in Pakistan.

Methodology: Data was extracted from Pakistan Demographic \& Health Surveys 2017-18. The sample size included 10,461 non-pregnant and married women from a total of 15,068 ever-married women. The analysis was done using twolevel mixed-effects logistic regression for the binary outcome variable, i.e., current contraceptive use (yes/no).

Main Findings: Significant factors positively associated with contraceptive use at the individual level were women's education, wealth index, parity, age at first cohabitation, child mortality experience, and mass media exposure. Community attributes like region (Sindh, KPK, Balochistan as compared to Punjab), residence (rural as compared to urban) had an inverse relationship with contraceptive use. At the same time, women's education and an ideal number of children were the significant positive associates. Women's empowerment has though insignificant, but it has a positive impact on the use of contraceptives at both individual and community levels.

Applications of this study: Family planning programs can be extended by focusing on women residing in rural settings or in high fertility intentions communities, less educated and unprivileged younger women who had reduced the uptake of contraceptives. An increase in women's access to education, media exposure, employment, and women's empowerment can help attain Pakistan's contraceptive prevalence targets.

Novelty/Originality of this study: The current study's effect of individual and community-level factors was investigated using National-level data, mainly focusing on the role of mass media and women's autonomy.

Keywords: Contraceptive Use, Pakistan, Individual Level and Community Level Associates, Multi-level Analysis, PDHS.

\section{INTRODUCTION}

Pakistan has the highest population growth rate among all South Asian countries (Pasha, 2016; Nkoka et al., 2021). The problem of population growth in Pakistan is a big challenge as it harms the country's social, economic, and political efforts to develop the country. Pakistan ranked at the fifth rank as the population of Pakistan exceeds 217 million (Ayub et al., 2015).

From the four pillars of safe motherhood, family planning is considered the first and most important pillar to reduce maternal deaths (Kabagenyi et al., 2021). Pakistan has a low rate of contraception use, high rate of contraception discontinuation, high unmet need, and high rate of unwanted fertility (Sharif et al., 2021). Family planning methods help to slow down population growth. It is one of the significant components of the reproductive health program. It helps to encourage couples to limit or space the number of children they desire through different contraceptive methods (Sensoy et al., 2018). Out of seven million pregnancies in Pakistan, 39\% were unintended, $28 \%$ ended as miscarriage, and $15 \%$ terminated in abortion (Pasha, 2016). United Nations (UN), 1995 Millennium Development Goals (MDGs) prepared the global strategy for women and children in 2010 to increase contraceptive use so that the women (MDG 4) and child mortality (MDG 5) can be reduced. Contraceptive use had risen in Pakistan from 12\% in 1990-91 to 35\% in 2012-13 and again declined to 34\% in 2017-18 (National Institute of Population Studies, 2019). MDG's targeted to increase the Contraceptive Prevalence Rate (CPR) to 55\% in 2015 (Planning Commission, 2010 as cited in PDHS 2012-13). However, the goal is still not attained despite the public and private organizations (Azmat, 2017). In Pakistan, an increase in contraceptive prevalence rate has slowed down, and no apparent socioeconomic reason could be found for this slow progress (Hardee \& Leahy, 2008). Currently, it is a challenge to find out how to increase contraceptive use and consequently control fertility (Sathar, 2013; Bornstein et al., 2020).

The utilization of mass media exposure plays a key role in the promotion of contraceptive use. Mass media promotes family planning methods and makes populations aware of the benefits of family planning. Previous researches showed that exposure through media spread the information, enhances the knowledge regarding the adoption of family planning methods, and help to transform people's behavior towards contraceptive use (Alemayehu et al., 2012; Bankole, 1994; Gizaw \& Regassa, 2011; Kiragu et al., 1996). In addition, improved mass media exposure among women has created awareness about contraceptive use and promoted increased use of contraceptive methods (Elfstrom \& Stephenson, 2012). 
The low social status of a woman within the household is a common factor that affects women's and their children's health. Kabeer (2001) defined women's empowerment as "the expansion of people's ability to make strategic life choices in a context where this ability was previously denied to them" (Karim et al., 2021). Women's autonomy is a predominant factor influencing a couple's decision to access reproductive health facilities and family planning methods. Therefore, efforts should be made to enhance women's empowerment and other structural drivers of contraceptive use (Prata et al., 2017). Women's empowerment played a significant role in lowering fertility, reduce unintended pregnancies, and longer birth intervals (Upadhyay et al., 2014; $\underline{\text { Islam et al., 2020). }}$.

This study aims to identify the role of individual and community-level factors, mainly focusing on mass media exposure and women's autonomy on contraceptive use in Pakistan.

\section{LITERATURE REVIEW}

Women with media exposure at both individual-level and community-level used contraception more than those not exposed to any media in Tanzania (Jato et al., 1999). The same was observed in the study of Sub-Saharan African countries (Stephenson et al., 2007; Jabeen et al., 2020). In Nigeria, it was found that $46.9 \%$ of the women who had media exposure favored using contraceptive methods compared to those who had no exposure (Etukudo, 2015). Access to mass media affected intentions to use contraceptives to control births and the ever use/current use of family planning methods in Kenya (Westoff \& Rodriguez, 1995). Mass media campaigns improve women's reproductive health by giving them awareness about family planning and social marketing (Basten, 2009; Gupta et al., 2003; Jah et al., 2014; Van Rossem \& Meekers, 2000).

Reproduction is not only the women's responsibility, but it is a dual commitment of the couple. Men have a significant role in using contraceptives or decision-making about the attitude towards contraceptives (Ayub et al., 2015). Men's involvement while supporting their wives in health problems, fertility, and birth spacing may increase contraceptive use, and the population can be controlled (Mahmood et al., 2000). In Pakistan, women have not authority to decisions regarding their reproductive health and the need for family planning (Saleem \& Bobak, 2005). Bangladeshi husbands do not accept the smaller family size (Piet-Pelon \& Ubaidur Rob, 1996). A cross-sectional study in Gaza showed that 68\% of the women do not use any contraceptive method due to the husband's opposition (Sahin \& Sahin, 2003). Men dominated decision-making regarding the use of contraceptives in Yemen (Almualm \& Khamis, 2007). The large family size in Pakistan is due to the desire for having more living sons in the family (Haider et al., 2009). Previous studies had shown that if a woman chooses to select her husband, she can communicate and participate in decisions about using family planning methods and other fertility issues (Fox, 1975; Ghimire et al., 2006; Gage, 1995; Xiaohe \& Whyte, 1990). Almost half of the studies found that women's autonomy has a significant positive association with the use of contraceptive methods (Prata et al., 2017). In South Asia, primarily women sacrifice their desire to plan their families and regulate their fertility due to a lack of empowerment to participate in decision making (Hameed et al., 2014).

Besides media exposure and women's autonomy, other potential factors are related to women's current contraceptive use (Tessema et al., 2021). These are women's age, education attainment, wealth index, number of living children, spousal communication, ideal family size, fertility preference, son preference, husband's desire for children with contraceptive use, and other dominating factors (Zelalem et al., 2021).

In South Asia, the emphasis on the individual level characteristics has not been able to clarify the changes in infertility issues (Pasha, 2016). Dev et al. (2002) stated that even though the choice to utilize contraception or to decide the number of children is determined at the degree of the household level, but in South Asia, it is determined considerably more by the community (Khan et al., 2020). Accordingly, there is a need for research that takes into consideration among and inside the individual-level, the household-level, and the community-level as well. Community-related components, including spousal roles, social standards, religion, and acknowledgment by the community, had a substantial role in

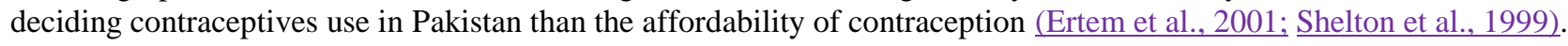

\section{METHODOLOGY}

\section{Data:}

The data used in the current analysis was extracted from Pakistan Demographic \& Health Survey, i.e., PDHS (2017-18) (Pakistan Demographic and Health Survey 2017-18. PKIR71.DTA. Rockville, Maryland: National Institute of Population Studies, 2014).

DHS surveys involve the complex sampling procedure for the selection of samples. A two-stage stratified clustered sampling design was adopted to collect data in the survey. First, the sample was taken from a sampling frame for rural areas that includes all the villages. Second, a sample of urban regions was selected using sampling frames consisting of enumeration blocks of approximately 200-250 households. The sampling frame used was prepared by the Pakistan Bureau of Statistics. Each block is known as Primary Sampling Units (PSUs). In the PDHS sample, PSUs are villages/mouzas for rural areas and enumeration blocks for urban areas.

PDHS collects data from women of reproductive age (15-49 years). The total sample size of ever-married women comprised 15,068 for PDHS (2017-18). In the current analysis, only currently married, non-pregnant women of Punjab, 
Sindh, Baluchistan, and KPK were extracted and analyzed. After applying the restrictions mentioned, the sample size was reduced to 10,461 women.

\section{Dependent Variable}

The outcome measure in this study was 'current contraceptive use' among non-pregnant and currently married women. Women who used any method of contraceptives (male or female condoms, pills, implants, injectables, foam, or jelly) were labeled as 'Yes' category, and non-users of any method contraceptive method were labeled as 'No' category.

\section{Independent Variables}

Based on the previous studies, independent variables were divided into two main groups: individual-level factors and community-level factors. Individual-level variables include demographic variables: age, age at first marriage, no. of living children, child mortality experience, socioeconomic variables: education level, employment status, wealth index, women's empowerment, and access to information: Exposure to mass media.

The mass media exposure variable was generated from three separate variables available in the dataset, i.e., heard family planning on radio last few months, heard family planning on TV last few months, and attended family planning in newspaper/magazine last few months. In contrast, the women's empowerment factor was generated using indicators (women's participation in making household decisions) (National Institute of Population Studies, 2014). It uses the following variables: a person who usually decides on respondent's health care, the person who usually determines on large household purchases, and usually decides on visits to family or relatives (Wu et al., 2020).

PDHS did not provide the data that reports the women's attributes at the community level except region and place of residence. Therefore, community-level factors were derived from individual-level data of all respondents residing in the community in each PSU's. Community-level factors were categorized into two groups (high-level \& low-level) by comparing the community-level value with the national mean value of each variable.

\section{Data analysis}

The analysis was carried out in STATA 14.0. DHS provides a hierarchical data structure, i.e., a nested data structure which includes clustering; therefore, a multi-level modeling approach was used in the statistical analysis. Multi-level models are also known as the random effect model/mixed effect model/random coefficient model/hierarchical model. It examines the cluster-level effect on an individual outcome variable. It also allows perceiving the individual-community level effect on the response factor.

In the current study, multi-level logistic regression was applied for the analysis as the outcome variable (everyday contraceptive use) was binary. The odds ratio was measured in the fixed-effect part of the model. In contrast, random intercept variance, intra-class correlation coefficient, and proportional change in variance were measured in the randomeffect part of the model.

Model strategy in the analysis included four models, i.e., Model 1 contained no predictor variables (individual-level or community-level). Model 2 had only individual-level factors, and Model 3 included only community-level factors. Finally, Model 4 used both individual-level and community-level factors to determine their combined effect on contraceptive use.

\section{Ethical Considerations}

Pakistan Demographic and Health Survey (PDHS) is part of the worldwide Demographic and Health Survey (DHS) Program. The survey is conducted by the National Institute of Population Studies (NIPS), 2019, with the funding and methodological support of ICF and USAID. Interview in DHS is initiated after getting the consensus of the respondent. DHS data is freely accessible, and there is no requirement for ethical approval before using this data. Permission to download and use data for the current research has been taken from DHS. Ethical approval has also been obtained from Author's Institute to carry out the current study.

\section{RESULTS/FINDINGS}

\section{Descriptive Analysis:}

In this study, a total of 10,461 married and non-pregnant women who resided in Punjab, Sindh, KPK, and Baluchistan were included. Of these women, only $(38.6 \%)$ were contraceptive users. The most commonly used contraceptive modern methods were female sterilization, withdrawal, and male condoms. The use of male sterilization and other natural methods was observed negligible. These findings of the percentage of contraceptive users are summarized in Figure 1.

The lowest percentage (18.2\%) of responders were women aged 15-24 years. The majority of the respondents were concentrated between 25-34 and above, age 35, respectively. More than half $(51.1 \%)$ of the women received an education, while $(48.9 \%)$ of the women were uneducated. On the other hand, a majority (70.2\%) of the husbands were educated. The highest percentage of respondents belonged to the wealthier households $(42.3 \%)$. The majority of the women $(25.5 \%)$ had only one living child, while only (14.2\%) of the women had more than six children. Almost two- 
thirds $(65.1 \%)$ of women entered into cohabitation after 18 years. Approximately $80 \%$ of the women had not experienced child mortality. Only $16.9 \%$ of women reported that they were employed. About one-fourth (24.2\%) of women had media (radio/television/magazine) exposure. A lower percentage of empowered women had been observed $(48.5 \%)$ than less empowered women.

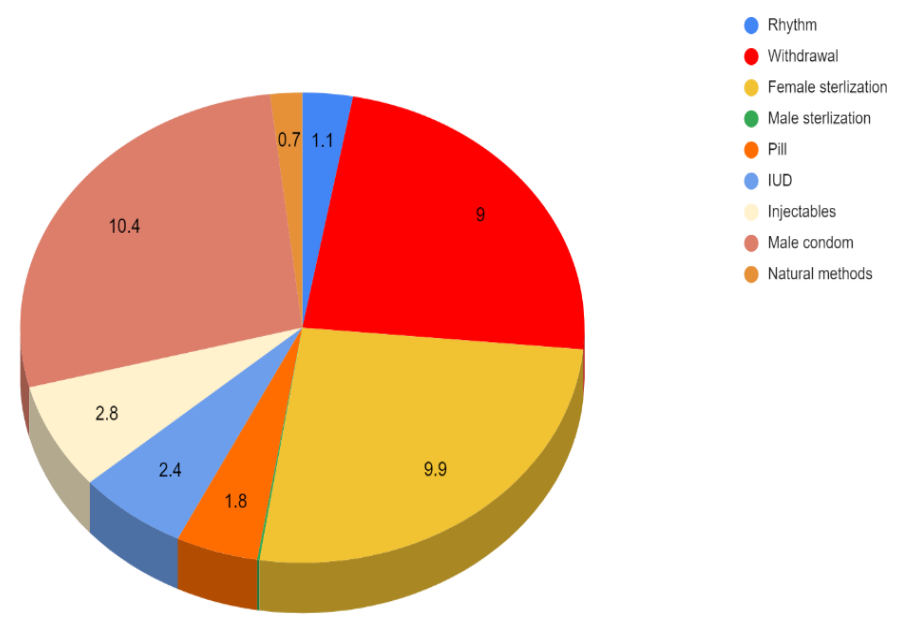

Figure 1: Percentage of Contraceptive Method Users by Type (PDHS 2017-18)

Table 1: Background Characteristics of Married \& Nonpregnant Women of Reproductive Age (15-49), PDHS 2017-18

\begin{tabular}{|c|c|c|c|}
\hline Individual Variables & Frequency $(\%)$ & Individual Variables & Frequency $(\%)$ \\
\hline Age & & Child Mortality Experience & \\
\hline $15-24$ & $1905(18.2)$ & No & $8318(79.5)$ \\
\hline $25-34$ & $4160(39.8)$ & Yes & $2143(20.5)$ \\
\hline $35+$ & $4397(42.0)$ & & \\
\hline Women's Education & & Women's Employment Status & \\
\hline No & $5112(48.9)$ & No & $8692(83.1)$ \\
\hline Yes & $5349(51.1)$ & Yes & $1767(16.9)$ \\
\hline Wealth Index & & Husband's Education & \\
\hline Poor & $3898(37.3)$ & No & $3105(29.8)$ \\
\hline Middle & $2139(20.5)$ & Yes & $7323(70.2)$ \\
\hline Rich & $4424(42.3)$ & & \\
\hline Parity & & Media Exposure & \\
\hline $0-1$ & $2671(25.5)$ & No & $7927(75.8)$ \\
\hline 2 & $1740(16.6)$ & Yes & $2534(24.2)$ \\
\hline 3 & $1738(16.6)$ & & \\
\hline 4 & $1640(15.7)$ & & \\
\hline 5 & $1184(11.3)$ & & \\
\hline $6+$ & $1487(14.2)$ & & \\
\hline Age at 1st Cohabitation & & Women's Empowerment & \\
\hline
\end{tabular}




\begin{tabular}{llll}
\hline$<18$ & $3651(34.9)$ & No & $5383(51.5)$ \\
\hline$>18$ & $6810(65.1)$ & Yes & $5077(48.5)$ \\
\hline
\end{tabular}

Table 2: Background Characteristics of Married \& Nonpregnant Women of Reproductive Age (15-49) by Cluster, PDHS 2017-18

\begin{tabular}{llll}
\hline Community-level variables & Frequency $(\%)$ & Community-level variables & Frequency (\%) \\
\hline Region & & Wealth Index & $6760(64.6)$ \\
\hline Punjab & $5581(54.8)$ & Low & $3701(35.4)$ \\
\hline Sindh & $2452(24.1)$ & High & \\
\hline KPK & $1616(15.8)$ & & $5634(53.9)$ \\
\hline Baluchistan & $527(5.1)$ & & $4827(46.1)$ \\
\hline Place of residence & & Ideal no. of children & \\
\hline Urban & $3928(37.5)$ & $<4$ & $5123(44.1)$ \\
\hline Rural & $6533(62.5)$ & $>=4$ & $5338(55.9)$ \\
\hline Women's Education & & Media exposure level & \\
\hline Lower & $5794(55.4)$ & Low & High \\
\hline Higher & $4667(44.6)$ & High & \\
\hline Husband's Education & & Women's empowerment level & \\
\hline Lower & $5936(56.7)$ & Low & \\
\hline Higher & $4525(43.3)$ & High & \\
\hline
\end{tabular}

The majority of the respondents belonged to Punjab, followed by Sindh, KPK, and Baluchistan, and belonged to rural settings $(62.5 \%)$. More than half $(55.4 \%)$ of women resided in the community that had lower women's education level than the national level. The percentage of women interviewed who lived in communities with a higher level of husband's education was $43.3 \%$. Approximately two-thirds of respondents $(64.6 \%)$ belonged to communities with a low level of wealth index. More than half $(53.9 \%)$ of the women lived in communities that had common fertility intentions $(<4$ children). It is interesting to note that in $2017-18$, more than half $(55.9 \%)$ of the communities, including married and non-pregnant women, were exposed to a high level of mass media compared to the proportion of communities who had less media exposure. The majority of women (62.5\%) lived in communities that had reported a lower level of women's empowerment.

Table 3: Multilevel Logistic Regression Model Identifying Factors Affecting the Use of Contraceptive Methods, (PDHS 2017-18)

\begin{tabular}{|c|c|c|c|c|c|c|c|c|c|}
\hline \multirow[t]{4}{*}{ Characteristics } & \multirow{4}{*}{$\begin{array}{l}\text { Null } \\
\text { Model }\end{array}$} & \multirow{3}{*}{\multicolumn{2}{|c|}{$\begin{array}{l}\text { Unadjusted Odds } \\
\text { Ratio }\end{array}$}} & \multicolumn{6}{|c|}{ Adjusted Odds Ratio } \\
\hline & & & & \multirow{2}{*}{\multicolumn{2}{|c|}{$\begin{array}{l}\text { Model I } \\
\text { Individual-level } \\
\text { variables }\end{array}$}} & \multirow{2}{*}{\multicolumn{2}{|c|}{$\begin{array}{l}\text { Model II } \\
\text { Community-level } \\
\text { variables }\end{array}$}} & \multirow{2}{*}{\multicolumn{2}{|c|}{$\begin{array}{l}\text { Model III } \\
\text { Individual } \\
\text { community-level } \\
\text { variables }\end{array}$}} \\
\hline & & & & & & & & & \\
\hline & & UOR & $95 \% \mathrm{CI}$ & AOR & $95 \% \mathrm{CI}$ & AOR & $95 \% \mathrm{CI}$ & AOR & $95 \% \mathrm{CI}$ \\
\hline \multicolumn{10}{|l|}{ Fixed effects } \\
\hline \multicolumn{10}{|l|}{$\begin{array}{l}\text { Age } \quad(\text { ref. }=15- \\
24)\end{array}$} \\
\hline $25-34$ & $-\cdots$ & 2.51 & $2.21-2.84$ & $0.82^{*}$ & $0.71-0.96$ & --- & --- & $0.82^{*}$ & $0.68-0.99$ \\
\hline $35+$ & --- & $2.94^{*}$ & $2.60-3.32$ & $0.59^{*}$ & $0.49-0.70$ & --- & --- & $0.55^{*}$ & $0.45-0.69$ \\
\hline $\begin{array}{l}\text { Women's } \\
\text { Education } \\
\text { (ref.= No) }\end{array}$ & & & & & & & & & \\
\hline
\end{tabular}


Humanities \& Social Sciences Reviews elSSN: 2395-6518, Vol 9, No 3, 2021, pp 764-775 https://doi.org/10.18510/hssr.2021.9375

\begin{tabular}{|c|c|c|c|c|c|c|c|c|c|}
\hline Yes & --- & $1.43^{*}$ & $1.30-1.56$ & $1.69^{*}$ & $1.51-1.89$ & --- & --- & $1.51^{*}$ & $1.32-1.73$ \\
\hline \multicolumn{10}{|c|}{$\begin{array}{l}\text { Wealth Index } \\
\text { (ref.= poor) }\end{array}$} \\
\hline Middle & --- & $1.60^{*}$ & $1.42-1.80$ & $1.59^{*}$ & $1.39-1.81$ & --- & -- & $1.41^{*}$ & $1.20-1.66$ \\
\hline Rich & --- & $1.87^{*}$ & $1.67-2.10$ & $1.91^{*}$ & $1.67-2.19$ & $-\cdots$ & --- & $1.52^{*}$ & $1.27-1.82$ \\
\hline \multicolumn{10}{|c|}{$\begin{array}{l}\text { Parity (ref.=0- } \\
\text { 1) }\end{array}$} \\
\hline 2 & --- & $5.34^{*}$ & $4.57-6.23$ & $5.78^{*}$ & $4.93-6.79$ & --- & --- & $6.35^{*}$ & $5.21-7.74$ \\
\hline 3 & $-\cdots$ & $8.59^{*}$ & $7.37-10.0$ & $10.51^{*}$ & $8.88-12.44$ & --- & --- & $10.66^{*}$ & $8.64-13.15$ \\
\hline 4 & --- & $10.68^{*}$ & $9.13-12.49$ & $15.01^{*}$ & $12.53-17.98$ & --- & --- & $15.68^{*}$ & $\begin{array}{l}12.54- \\
19.61 \\
\end{array}$ \\
\hline 5 & --- & $11.70^{*}$ & $9.88-13.84$ & $18.24^{*}$ & $14.98-22.21$ & --- & --- & $18.21^{*}$ & $\begin{array}{l}14.28- \\
23.22\end{array}$ \\
\hline $6+$ & --- & $10.47^{*}$ & $8.92-12.28$ & $19.00^{*}$ & $15.56-23.18$ & --- & --- & $21.15^{*}$ & $\begin{array}{l}16.51- \\
27.08 \\
\end{array}$ \\
\hline \multicolumn{10}{|c|}{$\begin{array}{l}\text { Age at } 1^{\text {st }} \\
\text { cohabitation } \\
(\text { ref.= }=<18)\end{array}$} \\
\hline$>=18$ & --- & $0.84^{*}$ & $0.77-0.91$ & 1.07 & $0.97-1.18$ & --- & --- & $1.12^{*}$ & $1.01-1.26$ \\
\hline \multicolumn{10}{|l|}{$\begin{array}{l}\text { Child } \\
\text { mortality } \\
\text { experience } \\
\text { (ref.= No) }\end{array}$} \\
\hline Yes & --- & $1.34^{*}$ & $1.21-1.48$ & $1.11^{*}$ & $1.01-1.24$ & $-\cdots$ & --- & $1.14^{*}$ & $1.01-1.30$ \\
\hline \multicolumn{10}{|c|}{$\begin{array}{l}\text { Women's } \\
\text { Employment } \\
\text { status } \\
\text { (ref.=No) }\end{array}$} \\
\hline Yes & --- & $1.22^{*}$ & $1.09-1.37$ & $1.15^{*}$ & $1.01-1.31$ & --- & --- & 1.12 & $0.96-1.31$ \\
\hline \multicolumn{10}{|l|}{$\begin{array}{l}\text { Husband's } \\
\text { Education } \\
\text { (ref.= No) }\end{array}$} \\
\hline Yes & --- & $1.27^{*}$ & $1.15-1.40$ & 1.10 & $0.98-1.23$ & --- & $\begin{array}{ll}-- \\
\end{array}$ & 1.12 & $0.98-1.27$ \\
\hline \multicolumn{10}{|l|}{$\begin{array}{l}\text { Media } \\
\text { Exposure } \\
\text { (ref.= No) } \\
\end{array}$} \\
\hline Yes & --- & $1.40^{*}$ & $1.27-1.54$ & $1.21^{*}$ & $1.08-1.35$ & --- & --- & $1.15^{*}$ & $1.01-1.32$ \\
\hline \multicolumn{10}{|c|}{$\begin{array}{l}\text { Women's } \\
\text { Empowerment } \\
\text { (ref.= No) }\end{array}$} \\
\hline Yes & --- & $1.46^{*}$ & $1.34-1.58$ & 1.07 & $0.98-1.18$ & --- & --- & 1.04 & $0.93-1.16$ \\
\hline \multicolumn{10}{|c|}{$\begin{array}{l}\text { Community- } \\
\text { level factors }\end{array}$} \\
\hline \multicolumn{10}{|c|}{$\begin{array}{l}\text { Region } \\
\text { (ref.=Punjab) }\end{array}$} \\
\hline Sindh & --- & $0.71^{*}$ & $0.57-0.87$ & --- & --- & $0.72^{*}$ & $0.59-0.86$ & $0.79^{*}$ & $0.65-0.95$ \\
\hline KPK & --- & 0.84 & $0.67-1.04$ & --- & --- & 0.91 & $0.75-1.11$ & 0.89 & $0.73-1.09$ \\
\hline Baluchistan & --- & $0.31^{*}$ & $0.24-0.40$ & --- & --- & $0.44^{*}$ & $0.34-0.57$ & $0.47^{*}$ & $0.36-0.61$ \\
\hline \multicolumn{10}{|c|}{$\begin{array}{l}\text { Place of } \\
\text { Residence } \\
\text { (ref.=Urban) }\end{array}$} \\
\hline Rural & --- & $0.56^{*}$ & $0.49-0.65$ & --- & --- & $0.67^{*}$ & $0.56-0.79$ & $0.78^{*}$ & $0.65-0.94$ \\
\hline \multicolumn{10}{|c|}{$\begin{array}{l}\text { Women's } \\
\text { Education } \\
\text { (ref.=low level) }\end{array}$} \\
\hline High level & --- & $2.32^{*}$ & $2.04-2.63$ & --- & --- & $1.45^{*}$ & $1.18-1.78$ & $1.30^{*}$ & $1.05-1.62$ \\
\hline \multicolumn{10}{|c|}{$\begin{array}{l}\text { Husband's } \\
\text { Education } \\
\text { (ref.=low level) }\end{array}$} \\
\hline High level & --- & 0.98 & $0.91-1.06$ & --- & $-\cdots$ & 0.98 & $0.89-1.07$ & 0.97 & $0.87-1.07$ \\
\hline
\end{tabular}




\begin{tabular}{|c|c|c|c|c|c|c|c|c|c|}
\hline $\begin{array}{l}\text { Wealth Index } \\
\text { (ref.=low) }\end{array}$ & & & & & & & & & \\
\hline High & --- & $0.54^{*}$ & $0.50-0.59$ & --- & --- & $0.55^{*}$ & $0.50-0.61$ & 0.93 & $0.82-1.05$ \\
\hline $\begin{array}{l}\text { Ideal no. of } \\
\text { children } \\
(\text { ref. }=<4)\end{array}$ & & & & & & & & & \\
\hline$>=4$ & $-\cdots$ & $0.48^{*}$ & $0.42-0.56$ & --- & $-\cdots$ & $0.74^{*}$ & $0.62-0.89$ & $0.73^{*}$ & $0.60-0.87$ \\
\hline $\begin{array}{l}\text { Media } \\
\text { Exposure } \\
\text { (ref.=No) }\end{array}$ & & & & & & & & & \\
\hline Yes & --- & $1.60^{*}$ & $1.39-1.85$ & --- & $-\cdots$ & 1.03 & $0.88-1.21$ & 0.95 & $0.80-1.12$ \\
\hline $\begin{array}{l}\text { Women's } \\
\text { Empowerment } \\
\text { (ref.=No) }\end{array}$ & & & & & & & & & \\
\hline Yes & --- & $1.15^{*}$ & $1.01-1.32$ & --- & $-\cdots$ & 1.05 & $0.92-1.21$ & 1.08 & $0.94-1.24$ \\
\hline $\begin{array}{l}\text { Random } \\
\text { Effects }\end{array}$ & & & & & & & & & \\
\hline $\begin{array}{l}\text { Random } \\
\text { intercept } \\
\text { variance } \\
\end{array}$ & 0.55 & & & 0.37 & & 0.24 & & 0.22 & \\
\hline$(\mathrm{ICC} \%)$ & 14.3 & & & 10.2 & & 7.0 & & 6.4 & \\
\hline$(\mathrm{PCV} \%)$ & Reference & & & 32.7 & & 56.3 & & 60.0 & \\
\hline
\end{tabular}

$* P<0.05$

Across the clusters, significant variability in contraceptive use was estimated by random intercept variance $(0.55)$ in an empty model (Table 3). Community-level factors explained $14.3 \%$ of the overall variation in using contraceptive methods. A low degree of correlation among individuals using contraceptive methods within a particular cluster (6.4\%) was due to the combined effect of individual-level and community-level variables (Model 3). Small ICC represents the good fitted model (Park \& Lake, 2005). Therefore, it was concluded that Model 3 is an excellent fitted model.

At the individual level, all factors except age at first cohabitation, husband's education, and women's empowerment were significantly associated with contraceptive use. All selected factors were associated with contraceptive use at the community level except husband's education, media exposure, and women's empowerment. In model 3, age at first cohabitation become significant when both community level and individual level factors were used. At the same time, women's employment (individual level) and wealth index (at community level) lost their significance. The behavior of the rest of the factors preserved in the combined model (Model 3) as observed in the individual level only model (Model 1) and community level only model (Model 2).

Individual-level factors explained $32.7 \%$ of the between cluster variation (PCV) in contraceptive methods. Women's age was observed to be significantly negatively associated with current contraceptive use. As the woman moved towards her end of reproductive age, her chances of using contraception had decreased $(0.59 ; 0.49-0.70)$ further. Compared with women's age (15-24), the odds of using contraceptives $(0.82 ; 0.71-0.96)$ were significantly lower for women with age (25-34). Higher odds for contraceptive use for educated women was observed $(1.69 ; 1.51-1.89)$ than the uneducated women. There was a gradual increase in the likelihood of using contraceptive methods with the wealth index. Women who belonged to middle wealthier households were $(1.59 ; 1.39-1.81)$ times more likely to use contraceptive methods than those who belonged to less wealthy households and it increased to $(1.91 ; 1.67-2.19)$ times for the women who belonged to the high wealthier households. A positive association was observed between parity and current contraceptive use. The chances of using contraceptives among women was low with low parity and higher for women with high parity. Women were (5.78; 4.93-6.79) times more likely to use contraceptive methods with two living children than women with at most one child. The odds ratio increased to $(19.0 ; 15.56-23.18)$ times for women having more than six living children relative to those with no or one living children. Women who had the first cohabitation at the age of above 18 present less chance of using contraception $(0.84 ; 0.77-0.91)$ than those who had the first cohabitation at less than 18 . The explanatory power of using contraceptives among women who had experienced child mortality had been observed more $(1.34 ; 1.21-1.48)$ than those who had not experienced child mortality. Employed women had (1.15; 1.01-1.31) higher odds of using contraceptive methods than unemployed women. Women with media exposure had (1.21; 1.08-1.35) higher odds of reporting contraceptive use than the women with no media exposure.

With the inclusion of community-level variables (Model 2), the proportion of explained variance showed that community level variables explained $56.3 \%$ of the community variance in contraceptive use. Compared to Punjabi women, women who lived in Sindh, KPK, and Baluchistan communities were $28 \%$, 9\%, and $56 \%$ less likely to use contraceptive methods, respectively. Respondents who lived in rural communities had 33\% lower contraceptive use odds than those who lived in urban communities. Women in the community with a higher level of education were (1.45; 1.18 1.78) times more likely to use contraceptive methods than those with a lower level of education. Communities with a 
high level of wealth index were $(0.55 ; 0.50-0.61)$ times less likely to use contraceptive methods than those communities with a low level of wealth index. The odds of using the contraceptive methods were $(0.74 ; 0.62-0.89)$ times less likely for the women who lived in communities with high fertility intentions (ideal family size of greater than 4) than those who lived in communities with low fertility intentions (perfect number of children of less than 4). Educated husbands in the community had lower odds $(0.98 ; 0.89-1.07)$ than uneducated husbands. Women in the community who had a high level of media exposure utilize more contraceptives $(1.03 ; 0.88-1.21)$ than those who had a low level of media exposure. Being empowered women in the community, they had higher odds $(1.05 ; 0.92-1.21)$ of using contraceptives than clusters with less empowered women.

By observing the results of Model 3, containing all individual and community variables, it was found that the trend in the effect of contraceptive use and individual \& community variables remained similar as observed in Model 1 and Model 2. PCV showed that $60.0 \%$ of all the variations associated with contraceptive use accounted for individual and communitylevel factors. The chances of using contraceptives among women belonged to age (15-24) and above age 35 were reduced to $(0.82 ; 0.68-0.99)$ odds and $(0.55 ; 0.45-0.69)$ odds in Model 3 . As expected, the log odds of using contraceptives were much higher for educated women than those with no education across the two models, but the odds of contraceptive use were reduced to $(1.51 ; 1.32-1.73)$ in the final model. With the addition of both individual-level and community-level variables, the odds of using contraception for women who belonged to middle and wealthier households were reduced to $(1.41 ; 1.20-1.66)$ and $(1.52 ; 1.27-1.82)$ times, respectively, as compared to those who belonged to less wealthy households. The pattern of contraceptive use we observed for parity was also observed for Model 3, except the odds increased in Model 3. Age at first cohabitation and child mortality experience showed significance in Model 3. The predictive power for the women who had their first cohabitation at the age of above 18 reported (1.12; 0.96-1.31) higher odds of using contraception than those who had cohabitation at the age of less than 18. Women who had experienced child mortality used contraceptives $(1.14 ; 1.01-1.30)$ times more likely than those who had not experienced child mortality. The likelihood of employed women lost its significance in the final model. Women who had media exposure had slightly reduced the explanatory power of women who had media exposure from 1.21 odds in Model 1 to $(1.15 ; 1.01-1.32)$ odds in Model 3. Comparing Model 2 and Model 3, results concluded that all significant community factors increased, except the women's education which reduced its odds in Model 3. In contrast, the odds of using contraceptive methods remained constant for the women who reported an ideal number of children greater than 4 . In addition, the community factor wealth index lost its significance in Model 3.

\section{DISCUSSION/ANALYSIS}

From the four pillars of safe motherhood, family planning is considered the first and most important pillar to reduce maternal deaths. However, a low prevalence of any method of contraceptive use in Pakistan was observed (34\%) in 2017 as compared to Bangladesh (62\%) in 2014, and in India (2015), it was 54\% (Ajmal et al., 2018). The lower rate of contraceptive use in Pakistan suggested that the small proportion of women were using contraceptives may not yet be sufficient to determine the rest of the factors even though the individual-only model explained the maximum variation. From this study, random intercept variance declared the significant variation in current contraceptive use, which implies that even with the inclusion of the most important and influential factors, there were unmeasured community characteristics responsible for cluster variation in contraceptive use in communities. These unobserved factors can directly affect contraceptive use, classified as socio-economic, demographic, cultural, psychological, behavioral, and environmental factors that could be analyzed at both individual and community levels (Kaggwa et al., 2008).

This study showed a negative association between women's age and current contraceptive use. The use of contraception decreases as the women's age increases. Older women of age (35+) were less likely to use contraceptives than younger women (15-24 years). This may be due to the reason that they have low fertility, as well as they, were using some other methods (string die) and avoid disclosing in the interview. Contrary to this, contraceptive use was more prevalent among younger women to increase birth spacing. The positive association between women's education and contraceptive use illustrates that more educated women were more aware of contraceptive methods and better access to health care services. It also helps to increase employment and empowerment possibilities, and so, unintended pregnancies can be reduced. The use of contraceptives increased with the household's wealth index, but the difference is minor. The household wealth index affects health behavior as it directly reflects the socioeconomic position of the household. A study concluded that less wealthy women could not use contraception due to expensive modern contraceptive methods and far locations from the place of residence of women who want to use contraceptive methods (Adebowale et al., 2016). To increase the efficiency of family planning services in Pakistan, the different suggestion was provided by improving family planning service quality, referrals and public sector management (Abbas et al., 2013). With the increase in parity, there was an increase in using contraceptives among women. It was concluded that women increase the use of contraceptives when they achieve their ideal number of children. Families also become even more challenging by more children for the associated additional expenses i.e., to provide better and higher education, food and clothing, shelter, and other health care services (Unumeri et al., 2015). Age at first cohabitation plays a significant importance in the problem of overpopulation. Women who were married and had the first cohabitation at the age of above 18 used more contraceptives than women who had the first cohabitation below 18 . Women at a very young age have more potential to bear a child and therefore, less contraceptive use had been observed among younger women. This is because they have achieved their desired family size at a very young age $(<18)$ and do not want any more children. Child 
mortality experience is observed to be a significant factor of contraceptive use but has a very low association level. Most women giving birth to the child within less than two years and experienced child mortality (Pati, 2003). Media exposure plays a vital role in improving health indicators. Mass media exposure had a significant positive effect on current contraceptive use and findings were in line with other studies (Abate \& Tareke, 2019; Carton \& Agha, 2012; Ejembi et al., 2015). A strong association between watching television and contraceptive use was reported for Pakistan (Mahmood \& Ringheim, 1996). The use of mass media (radio, television, internet, or cell phones) helps to enhance the use of different contraceptive methods among women to protect their maternal health. Also, mass media has a significant influence on population health status.

Residents in Punjab used more contraceptive methods compared with other regions Sindh, Baluchistan, and KPK. This is because the Punjab region is the most populated province of Pakistan (Pasha, 2016). Due to the large location and size of the region, Punjab also received many financial resources from the numerous efforts within the country (Nishtar et al., 2013). Urban dwellers had significantly higher chances of contraceptive use due to the high education, increased employment status, and much awareness about modern contraceptive methods. An increase in female education also increases the odds of using contraceptives at the community level due to women's empowerment which helps them make household decisions and enhance their social systems. High fertility intention prevents women from using contraceptives. Women who lived in communities with an ideal family size of greater than 4 children used fewer contraceptives than those who preferred a perfect family size of fewer than 4 children. Consistent results had been found in other countries, Mali and Nigeria (Kaggwa et al., 2008; Simiat, 2018). The fertility intentions of Pakistani women are also observed high compared to the government's declared ideal family size (National Institute of Population Studies, 2014). According to community norms, men and women both desired to have a large family size, i.e., as low as 4 and as high as $8-10$, due to several reasons. They think that if they have more children, there would be at least one who will help their parents in the future (Muanda et al., 2017). Women who lived in a community with high media exposure used more contraceptives due to the awareness and knowledge about different contraceptive methods. Finding for community-level women's empowerment showed that more empowered women in the community used more contraceptives due to increased employment, education, and self-independence. In terms of improved women's empowerment, women may be capable of making important decisions regarding their reproductive health and expanding their choices about family planning (Ejembi et al., 2015). Women who have more decision-making power, have more knowledge, higher wealth status, and participated in the labor market used more contraceptives (Yaya et al., 2018).

\section{CONCLUSION}

In this study, the effect of both individual-level and community-level factors on contraceptive use among women was determined. Significant factors positively associated with contraceptive use at the individual level were women's education, wealth index, parity, age at first cohabitation, child mortality experience, and mass media exposure. Community attributes like region (Sindh, KPK, Balochistan as compared to Punjab), place of residence (rural as compared to urban) had an inverse relationship with contraceptive use while women's education and the ideal number of children were the significant positive associates. Women's empowerment has an insignificant but positive impact on the use of contraceptives at both individual and community levels.

Family planning programs can be extended by focusing on women residing in rural settings or in high fertility intentions communities, less educated and unprivileged younger women who had less contraceptive uptake. In addition, an increase in women's access to education, media exposure, employment, and women's empowerment can help to attain the contraceptive prevalence targets in Pakistan.

\section{LIMITATION AND STUDY FORWARD}

The major strength of this research is that the use of PDHS national-level data is an authentic source for data collection worldwide. The hierarchical nature of DHS data gives the strength to explore community-level factors beyond the individual-level factors on current contraceptive use. In addition to the strengths, there are also some limitations. Some important factors related to fertility preferences and husband-related factors like the husband's desire for more children were not included in the analysis due to the high proportion of missing values.

Women empowerment factor was computed based on the availability of relevant data in PDHS. The idea can be extended by conducting a survey that addresses particularly different dimensions of women's empowerment and its impact on the use of contraceptives.

\section{ACKNOWLEDGEMENT}

I am very sincerely thankful to all my co-authors, Asifa Kamal, Hafsa Batool, and Afza Rasul who fully contribute to this research. I hope this research paper is beneficial to all potential researchers.

\section{AUTHORS CONTRIBUTION}

The introduction and literature review of this study was largely conceptualized by Sadaf Malik. Asifa Kamal has made a major contribution towards the conceptualization of the area of study, data collection from diverse sources, targeted 
public, discussions, and conclusions. The research concepts of the study and research methodology development and analysis by Hafsa Batool and Afza Rasul.

\section{REFERENCES}

1. Abate, M. G., \& Tareke, A. A. (2019). Individual and community-level associates of contraceptive use in Ethiopia: a multilevel mixed-effects analysis. Archives of Public Health, 77(1), 46. https://doi.org/10. 1186/s13690-019-0371-z

2. Abbas, K., Khan, A. A., \& Khan, A. (2013). Costs and utilization of public sector family planning services in Pakistan. JPMA. The Journal of the Pakistan Medical Association, 63(4 Suppl 3), S33-S39.

3. Adebowale, A. S., Gbadebo, B., \& Afolabi, F. R. (2016). Wealth index, empowerment and modern contraceptive use among married women in Nigeria: are they interrelated? Journal of Public Health, 24(5), 415-426. https://doi.org/10.1007/s10389-016-0738-3

4. Ajmal, S., Idris, A., \& Ajmal, B. (2018). Factors affecting contraceptive use and unmet need among currently married women in Afghanistan: further analysis of the 2015 Afghanistan Demographic and Health Survey. Journal of Global Health Reports, 2, e2018037. ttps://doi.org/10.29392/joghr.2.e2018037

5. Alemayehu, M., Belachew, T., \& Tilahun, T. (2012). Factors associated with utilization of long-acting and permanent contraceptive methods among married women of reproductive age in Mekelle town, Tigray region, north Ethiopia. BMC pregnancy and childbirth, 12(1), 1-9. https://doi.org/10.1186/1471-2393-12-6

6. Almualm, Y. K. A., \& Khamis, Y. (2007). Knowledge, attitude and practice of husbands towards modern family planning in Mukalla, Yemen. University Sains Malaysia. Retrieved from http://eprints.usm.my/293 28/1/Knowledge, attitude and practive of husband towards modern family planning.pdf

7. Ayub, A., Kibria, Z., \& Khan, F. (2015). Assessment of knowledge, attitude and contraceptive use in married women of Peshawar. J Dow Univ Health Sci, 9(1), 89-93.

8. Azmat, S. K. (2017). Models to accelerate modern family planning/contraceptive services access and uptake among married women in rural Pakistan. Ghent, Belgium: Ghent University. Faculty of Medicine and Health Sciences. Retrieved from http://hdl.handle.net/1854/LU-8514475

9. Bankole, Akinrinola. (1994). The role of mass media in family planning promotion in Nigeria. DHS Working Papers No. 11. Calverton, Maryland, USA: Macro International. Available at http://dhsprogram.com/pu bs/pdf/WP11/WP11.pdf

10. Basten, S. (2009). Mass media and reproductive behaviour: Serial narratives, soap operas and telenovelas. The Future of Human Reproduction: Working Paper, 7.

11. Bornstein, M., Huber-Krum, S., Kaloga, M., \& Norris, A. (2020). Messages around contraceptive use and implications in rural Malawi. Culture, Health \& Sexuality, 1-16. https://doi.org/10.1080/136910 58.2020.1764625

12. Carton, T. W., \& Agha, S. (2012). Changes in contraceptive use and method mix in Pakistan: 1990-91 to 200607. Health Policy and Planning, 27(2), 166-174. https://doi.org/10.1093/heapol/czr022

13. Casterline, J. B., Sathar, Z. A., \& ul Haque, M. (2001). Obstacles to contraceptive use in Pakistan: A study in Punjab. Studies in family planning, 32(2), 95-110. https://doi.org/10.1111/j.1728-4465.2001.00095.x

14. Dev, S. M., James, K. S., \& Sen, B. (2002). Causes of Fertility Decline in India and Bangladesh: Role of Community. Economic and Political Weekly, 37(43), 4447-4454. https://doi.org/10.1093/heapol/czr022

15. Ejembi, C. L., Dahiru, T., \& Aliyu, A. A. (2015). Contextual factors influencing modern contraceptive use in Nigeria. DHS Working Papers No. 120. Rockville, Maryland, USA: ICF International.

16. Elfstrom, K. M., \& Stephenson, R. (2012). The role of place in shaping contraceptive use among women in Africa. PloS one, 7(7), e40670. https://doi.org/10.1371/journal.pone.0040670

17. Ertem, M., Ergenekon, P., Elmaci, N., \& Ilcin, E. (2001). Family planning in grand multiparous women in Diyarbakir, Turkey, 1998: the factors affecting contraceptive use and choice of method. The European Journal of Contraception \& Reproductive Health Care, 6(1), 1-8. https://doi.org/10.1080/ejc.6.1.1.8

18. Etukudo, I. W. (2015). Information as Determinant of Utilization of Family Planning Services in Rural Akwa Ibom State of South-South Nigeria. Mediterranean Journal of Social Sciences, 6(4), 445-445. https://doi.org/10.5901/mjss.2015.v6n4s1p445

19. Fox, G. L. (1975). Love match and arranged marriage in a modernizing nation: Mate selection in Ankara, Turkey. Journal of Marriage and the Family, 37(1), 180-193. https://doi.org/10.2307/351042

20. Gage, A. J. (1995). Women's socioeconomic position and contraceptive behavior in Togo. Studies in family planning, 26(5), 264-277. https://doi.org/10.2307/2138012

21. Ghimire, D. J., Axinn, W. G., Yabiku, S. T., \& Thornton, A. (2006). Social change, premarital nonfamily experience, and spouse choice in an arranged marriage society. American Journal of Sociology, 111(4), 11811218. https://doi.org/10.1086/498468

22. Gizaw, A., \& Regassa, N. (2011). Family planning service utilization in Mojo town, Ethiopia: A populationbased study. Journal of Geography and Regional Planning, 4(6), 355-363.

23. Gupta, N., Katende, C., \& Bessinger, R. (2003). Associations of mass media exposure with family planning attitudes and practices in Uganda. Studies in family planning, 34(1), 19-31. https://doi.org/10.1111/j.17284465.2003.00019.x 
24. Haider, G., Parveen, N., Rani, S., \& Haider, A. (2009). Family planning practices and its awareness among multiparous women. Rawal Medical Journal, 34(2), 183-186.

25. Hameed, W., Azmat, S. K., Ali, M., Sheikh, M. I., Abbas, G., Temmerman, M., \& Avan, B. I. (2014). Women's empowerment and contraceptive use: the role of independent versus couples' decision-making, from a lower middle-income country perspective. PloS one, 9(8), e104633. https://doi.org/10.1371/journal.pone.0104633

26. Hardee, K., \& Leahy, E. (2008). Population, fertility and family planning in Pakistan: a program in stagnation. Population Action International, 3(3), 1-12. http://pai.org/wp-content/uploads/2012/01/pakistan.pdf

27. Islam, M. K., Haque, M. R., \& Hema, P. S. (2020). Regional variations of contraceptive use in Bangladesh: A disaggregate analysis by place of residence. PloS one, 15(3), e0230143. https://doi.org/10.1371/j ournal.pone.0230143

28. Jabeen, S., Rathor, A., Riaz, M., Zakar, R., \& Fischer, F. (2020). Demand-and supply-side factors associated with the use of contraceptive methods in Pakistan: a comparative study of demographic and health surveys, 1990-2018. BMC Women's Health, 20(1), 1-11. https://doi.org/10.1186/s12905-020-01112-4

29. Jah, F., Connolly, S., Barker, K., \& Ryerson, W. (2014). Gender and reproductive outcomes: the effects of a radio serial drama in Northern Nigeria. International Journal of Population Research, 2014. Article ID 326905, 24. https://doi.org/10.1155/2014/326905

30. Jato, M. N., Simbakalia, C., Tarasevich, J. M., Awasum, D. N., Kihinga, C. N., \& Ngirwamungu, E. (1999). The impact of multimedia family planning promotion on the contraceptive behavior of women in Tanzania. International Family Planning Perspectives, 25(2), 60-67. https://doi.org/10.2307/2991943

31. Kabagenyi, A., Wasswa, R., Henry, N., Paulino, A., Sseninde, J., \& Rusatira, J. C. (2021). Multilevel Mixed Effects Analysis of Individual and Community Factors Associated With Unmet Need for Contraception Among Married Women in Four East African Countries. https://doi.org/10.21203/rs.3.rs-470884/v1

32. Kabeer, Naila (2001). Reflections on the measurement of women's empowerment. In: Sisask, Anne, (ed.) Discussing Women's Empowerment: Theory and Practice. SIDA studies (3). Swedish International Development Cooperation Agency, Stockholm, Sweden, 17-57.

33. Kaggwa, E. B., Diop, N., \& Storey, J. D. (2008). The role of individual and community normative factors: a multilevel analysis of contraceptive use among women in union in Mali. International family planning perspectives, 34(2), 79-88. https://doi.org/10.1363/ifpp.34.079.08

34. Karim, S. I., Irfan, F., Saad, H., Alqhtani, M., Alsharhan, A., Alzhrani, A., ... \& MA Ahmed, A. (2021). Men's knowledge, attitude, and barriers towards emergency contraception: A facility-based cross-sectional study at King Saud University Medical City. PloS one, 16(4), e0249292. https://doi.org/10.1371/journal.pone.0249292

35. Khan, M. N., Harris, M., \& Loxton, D. (2020). Modern contraceptive use following an unplanned birth in Bangladesh: an analysis of national survey data. International perspectives on sexual and reproductive health, 46, 77-87. https://doi.org/10.1363/46e8820

36. Kiragu, K., Krenn, S., Kusemiju, B., Ajiboye, J., Chidi, I., \& Kalu, O. (1996). Promoting family planning through mass media in Nigeria: campaigns using public service announcements and a national logo. Baltimore, Maryland: John Hopkins Centre for Communication Programs. Retrieved from https://pdf.usaid.gov/pdf docs/Pnacg655.pdf

37. Mahmood, N., \& Ringheim, K. (1996). Factors affecting contraceptive use in Pakistan. The Pakistan Development Review, 1-22. https://doi.org/10.30541/v35i1pp.1-22

38. Mahmood, N., Durr-e-Nayab, \& Hakim, A. (2000). An Analysis of Reproductive Health Issues in Pakistan [with Comments]. The Pakistan development review, 39(4), 675-693. https://doi.org/10.30541/v39i4IIpp.675$\underline{693}$

39. Muanda, M. F., Ndongo, G. P., Messina, L. J., \& Bertrand, J. T. (2017). Barriers to modern contraceptive use in rural areas in DRC. Culture, health \& sexuality, 19(9), 1011-1023. https://doi.org/10.1080/13691 $\underline{058.2017 .1286690}$

40. National Institute of Population Studies. (2014). Pakistan Demographic and Health Survey 2012-13. Islamabad, Pakistan: National Institute of Population Studies [Pakistan] and Macro International Inc.

41. National Institute of Population Studies. (2019). Pakistan Demographic and Health Survey 2017-18. Islamabad, Pakistan: National Institute of Population Studies [Pakistan] and Macro International Inc.

42. Nishtar, N., Sami, N., Faruqi, A., \& Khowaja, S. (2013). Myths and fallacies about male contraceptive methods: a qualitative study amongst married youth in slums of Karachi, Pakistan. Global journal of health science, 5(2), 84. https://doi.org/10.5539/gjhs.v5n2p84

43. Nkoka, O., Lee, D., Chuang, K. Y., \& Chuang, Y. C. (2021). Multilevel analysis of the role of women's empowerment on use of contraceptive methods among married Cambodian women: evidence from demographic health surveys between 2005 and 2014. BMC Women's Health, 21(1), 1-13. https://doi.org/10. 1186/s12905-020-01141-Z

44. Park, S., \& Lake, E. T. (2005). Multilevel modeling of a clustered continuous outcome: nurses' work hours and burnout. Nursing Research, 54(6), 406. https://doi.org/10.1097/00006199-200511000-00007

45. Pasha, M. K. (2016). Investigating Pakistan's Contraception Rate Plateau: A Multilevel Analysis to Understand the Association between Community Contextual Factors and Modern Contraception Use. The University of South Florida, Tampa, Florida. Retrieved from https://scholarcommons.usf.edu/etd/6348/ 
46. Pati, R. N. (2003). Socio-cultural dimensions of reproductive child health: APH Publishing.

47. Piet-Pelon, N. J., \& Ubaidur Rob, A. K. (1996). Male involvement a challenge for the Bangladesh national family planning program. The Population Council of Bangladesh, Dhaka, Bangladesh. 17(2), 195-206. https://doi.org/10.2190/EQD9-PYMJ-U9RY-PVYU

48. Prata, N., Fraser, A., Huchko, M. J., Gipson, J. D., Withers, M., Lewis, S., ... \& Upadhyay, U. D. (2017). Women's empowerment and family planning: A review of the literature. Journal of biosocial science, 49(6), 713-743. https://doi.org/10.1017/S0021932016000663

49. Sahin, H. A., \& Sahin, H. G. (2003). Reasons for not using family planning methods in Eastern Turkey. The European Journal of Contraception \& Reproductive Health Care, 8(1), 11-16. https://doi.org/10.1080/ejc .8 .1 .11 .16

50. Saleem, S., \& Bobak, M. (2005). Women's autonomy, education and contraception use in Pakistan: a national study. Reproductive health, 2(1), 8. https://doi.org/10.1186/1742-4755-2-8

51. Sathar, Z. A. (2013). Family planning: a missing priority in Pakistan's health sector? Lancet (London, England), 381(9884), 2140-2141. https://doi.org/10.1016/S0140-6736(13)60763-1

52. Sensoy, N., Korkut, Y., Akturan, S., Yilmaz, M., Tuz, C., \& Tuncel, B. (2018). Factors affecting the attitudes of women toward family planning. Family Planning, 33. https://doi.org/10.5772/intechopen.73255

53. Sharif Hossain, P. S., Zieman, B., Roy, S., Kennedy, S., Hossain, I., \& Bellows, B. (2021). Measuring quality of care at the community level using the contraceptive method information index plus and client reported experience metrics in Bangladesh. Journal of Global Health, 11. https://doi.org/10.7189/jogh.11.07007

54. Shelton, J. D., Bradshaw, L., Hussein, B., Zubair, Z., Drexler, T., \& McKenna, M. R. (1999). Putting unmet need to the test: community-based distribution of family planning in Pakistan. International Family Planning Perspectives, 25(4), 191-195. https://doi.org/10.2307/2991884

55. Simiat, A. O. (2018). Community and Individual Level Factors Influencing Modern Contraceptive Use among Married Women in Nigeria. Health Sciences Research, 5(3), 59-68. http://www.aascit.org/journal/hsr

56. Stephenson, R., Baschieri, A., Clements, S., Hennink, M., \& Madise, N. (2007). Contextual influences on modern contraceptive use in sub-Saharan Africa. American journal of public health, 97(7), 1233-1240. https://doi.org/10.2105/AJPH.2005.071522

57. Tessema, Z. T., Teshale, A. B., Tesema, G. A., Yeshaw, Y., \& Worku, M. G. (2021). Pooled prevalence and determinants of modern contraceptive utilization in East Africa: A Multi-country Analysis of recent Demographic and Health Surveys. PloS one, 16(3), e0247992. https://doi.org/10.1371/journal.pone.0247992

58. United Nations. (1995). Millennium Development Goals and Beyond 2015, December 2, 2013, Retrieved from http://www.un.org/millenniumgoals/bkgd.shtml

59. Unumeri, G., Ishaku, S., Ahonsi, B., \& Oginni, A. (2015). Contraceptive use and its socio-economic determinants among women in North-East and North-West Regions of Nigeria: a comparative analysis. African Population Studies, 29(2). https://doi.org/10.11564/29-2-757

60. Upadhyay, U. D., Gipson, J. D., Withers, M., Lewis, S., Ciaraldi, E. J., Fraser, A., ... \& Prata, N. (2014). Women's empowerment and fertility: a review of the literature. Social science \& medicine, 115, 111-120. https://doi.org/10.1016/j.socscimed.2014.06.014

61. Van Rossem, R., \& Meekers, D. Akinyemi Z. (2000). Consistent condom use in Nigeria: evidence from two waves of sexual behavior and condom use survey. PSI Research Division Working Paper, 31, 1-21. https://doi.org/10.1521/aeap.13.3.252.19745

62. Westoff, C. F., \& Rodriguez, G. (1995). The mass media and family planning in Kenya. International family planning perspectives, 21(1), 26-36. https://doi.org/10.2307/2133602

63. Wu, W. J., Tiwari, A., Choudhury, N., Basnett, I., Bhatt, R., Citrin, D., ... \& Maru, S. (2020). Community-based postpartum contraceptive counselling in rural Nepal: a mixed-methods evaluation. Sexual and reproductive health matters, 28(2), 1765646. https://doi.org/10.1080/26410397.2020.1765646

64. Xiaohe, X., \& Whyte, M. K. (1990). Love matches and arranged marriages: A Chinese replication. Journal of Marriage and the Family, 52, 709-722. https://doi.org/10.2307/352936

65. Yaya, S., Uthman, O. A., Amouzou, A., Ekholuenetale, M., \& Bishwajit, G. (2018). Inequalities in maternal health care utilization in Benin: a population based cross-sectional study. BMC Pregnancy and Childbirth, 18(1), 1-9. https://doi.org/10.1186/s12884-018-1846-6

66. Zelalem, D., Worku, A., Alemayehu, T., \& Dessie, Y. (2021). Association of Effective Spousal Family Planning Communication with Couples' Modern Contraceptive Use in Harar, Eastern Ethiopia. Open Access Journal of Contraception, 12, 45. https://doi.org/10.2147/OAJC.S285358 